\title{
Human Milk Mucin Inhibits Rotavirus Replication and Prevents Experimental Gastroenteritis
}

Robert H. Yolken, * Jerry A. Peterson, ${ }^{*}$ Steven L. Vonderfecht, * Erik T. Fouts, * Karen Midthun," and David S. Newburg" Johns Hopkins University School of Medicine, *Department of Pediatrics and ${ }^{8}$ School of Public Health and Hygiene, Department of International Health, Baltimore, Maryland 21205; ${ }^{\ddagger}$ Cancer Research Fund of Contra Costa, Walnut Creek, California 94596 ; and "Shriver Center for Mental Retardation, Department of Biochemistry, Waltham, Massachusetts 02254

\begin{abstract}
Acute gastrointestinal infections due to rotaviruses and other enteric pathogens are major causes of morbidity and mortality in infants and young children throughout the world. Breastfeeding can reduce the rate of serious gastroenteritis in infants; however, the degrees of protection offered against rotavirus infection vary in different populations. The mechanisms associated with milk-mediated protection against viral gastroenteritis have not been fully elucidated.

We have isolated a macromolecular component of human milk that inhibits the replication of rotaviruses in tissue culture and prevents the development of gastroenteritis in an animal model system. Purification of the component indicates that the antiviral activity is associated with an acidic fraction ( $\mathrm{pI}=4.0$ 4.6), which is free of detectable immunoglobulins. Furthermore, high levels of antiviral activity are associated with an affinity-purified complex of human milk mucin. Deglycosylation of the mucin complex results in the loss of antiviral activity. Further purification indicated that rotavirus specifically binds to the milk mucin complex as well as to the $46-\mathrm{kD}$ glycoprotein component of the complex. Binding to the 46-kD component was substantially reduced after chemical hydrolysis of sialic acid.

We have documented that human milk mucin can bind to rotavirus and inhibit viral replication in vitro and in vivo. Variations in milk mucin glycoproteins may be associated with different levels of protection against infection with gastrointestinal pathogens. (J. Clin. Invest. 1992. 90:1984-198791.) Key words: rotavirus • mucin • human milk • gastroenteritis
\end{abstract}

\section{Introduction}

Acute infectious gastrointestinal diseases remain major causes of illness in infants and young children throughout the world. In developing regions of the world, infectious gastrointestinal diseases have been estimated to cause 12,000 deaths per day. Diarrheal disease is also an important health problem in developed countries. In the United States, over 200,000 children under 5 years of age are hospitalized each year with acute diarrheal disease, accounting for nearly 880,000 inpatient days,

Address reprint requests to Robert H. Yolken, M.D., Johns Hopkins University, Pediatric Infectious Diseases, 600 North Wolfe Street, Blalock 1111, Baltimore, MD 21205.

Received for publication 11 October 1991 and in revised form 11 May 1992.

J. Clin. Invest.

(c) The American Society for Clinical Investigation, Inc.

$0021-9738 / 92 / 11 / 1984 / 08 \$ 2.00$

Volume 90, November 1992, 1984-1991 over 500 deaths, and almost one billion dollars of inpatient cost per year $(1-3)$.

A number of viral, bacterial, and parasitic agents are known to cause acute infectious gastroenteritis (4-6). Rotaviruses have been identified as the most important viral agent of infantile gastroenteritis in children living in both developed and developing countries. Prospective studies in the United States indicate that rotaviruses account for 2.9 million episodes of diarrhea leading to 22,000 annual hospitalizations in children less than 5 years old $(2,5-7)$. Rotaviruses also have been implicated as causative agents of outbreaks of diarrhea occurring in nursing homes, travelers, day-care centers, and adult contacts of ill children. Additionally, rotaviruses have been identified as etiologic agents of diarrhea in patients undergoing bone marrow transplantation and suffering from a variety of immunodeficiency conditions (8-12). The recognition of the importance of rotaviral infections has led to a substantial effort directed at the prevention of infection by means of active immunization. However, current vaccine regimens have displayed variable degrees of efficacy, indicating the need for the better understanding of the mechanisms responsible for disease prevention $(5,13-17)$.

Breast-feeding has been recognized as an important factor in protection against enteric infection with other pathogens. Numerous studies have documented the fact that children who are breast-fed undergo substantially fewer total episodes of gastroenteritis compared with infants who are bottle fed. Although many of these studies are based on children living in developing countries (18-20), a protective effect of breast-feeding has also been documented in infants living in developed countries such as Great Britain and the United States $(21,22)$. Breastfeeding has also been shown to lower the incidence of enteric diseases, such as necrotizing enterocolitis of infancy, which may be infectious in origin but have not been associated with a single etiologic agent (23). On the other hand, the protective effect of breast-feeding on gastroenteritis caused by rotaviruses has been variable. Breast-feeding does not provide total protection against infection and serious episodes of rotavirus infection have been noted in breast-fed infants (24-26). However, in many populations, breast-feeding lessens the severity of diarrhea and vomiting associated with rotavirus infection in hospitalized children (26-28). The degree of protection offered by human milk correlates only partially with the levels of antirotavirus antibodies measured in the milk, suggesting that nonimmunoglobulin factors may play a role in the protective process $(29,30)$.

Human milk contains numerous nonimmunoglobulin factors that can inhibit the replication of microorganisms (3133 ). We have previously found that mucins and related sialic acid-containing glycoproteins of animal origin can inhibit the in vitro replication of rotaviruses in cell culture. The inhibitory activity of these glycoproteins is dependent upon the presence 
of sialic acids and their function appears to be related to interference with viral binding to sialic acid containing cellular receptors (34-36). We now report on the antirotaviral activity of mucin and mucinous components found in human milk.

\section{Methods}

\section{Preparation of milk fractions}

Source. Milk was obtained from 30 healthy lactating donors to the Central Massachusetts Regional Milk Bank, Worcester, MA. The samples were chosen to represent a wide selection of maternal age $(28 \pm 4 \mathrm{y}$; range: 20-37 y), parity ( 9 primiparous, 13 secundiparous, 5 tertiparous, 3 quadriparous), and maturity of milk ( $6.0 \pm 3.8$ mon postpartum; range: $0-14 \mathrm{mo}$ ). Milk was generally expressed in the morning by use of a mechanical pump. The milk was pooled and individual fractions were prepared by the following methods:

Oligosaccharides. Oligosaccharide fractions of human milk were prepared using methods that we have previously devised for this purpose (37). The milk was centrifuged at $4^{\circ} \mathrm{C}$ at $3,000 \mathrm{~g}$ for $1 \mathrm{~h}$. The cream was removed and the skimmed milk was filtered through glass wool. The filtrate was mixed with an equal amount of ice-cold acetone, stirred overnight at $4^{\circ} \mathrm{C}$, and centrifuged at $3,000 \mathrm{~g}$ for $45 \mathrm{~min}$. The clear supernatant was concentrated by rotary evaporation and applied to a 1-liter charcoal-Celite column. After extensive washing with distilled water and 5\% ethanol (aqueous), the oligosaccharide fraction was eluted from the column with $50 \%$ ethanol (aqueous). The eluate was passed through anion exchange resin (AG 1-X2; Bio-Rad Laboratories, Richmond, CA) to yield the neutral oligosaccharide fraction. The acidic oligosaccharides were eluted from the resin with $1 \mathrm{M}$ formic acid, dialyzed, and lyophilized. The fractions were stored at $-70^{\circ} \mathrm{C}$ until tested.

Lipids. Lipid fractions were prepared by the following method: Milk was extracted with $20 \mathrm{vol}$ of chloroform/methanol (2:1), filtered, and dried. The lipid was then partitioned between hexane and $88 \%$ aqueous ethanol. Free fatty acids were removed from the hexane fraction by washing with methanolic ammonia, and the fatty acids were recovered by acidifying the methanol and extracting the protonated fatty acids with hexane. The ethanol fraction was subjected to Folch partition; the upper-phase lipids were isolated on a reversed-phase column and then separated on DEAE Sepharose (Pharmacia, Uppsala, Sweden) into the neutral glycolipids and the anionic glycolipids (indicated as the "neutral" and "ganglioside" fractions, see Fig. 1). The Folch lower-phase lipids were separated on a silicic acid column (Unisil; Clarkson Chemical, Williamsport, PA) to isolate the lower phase glycolipid fraction.

Macromolecular fraction. The milk was subjected to three freezethaw cycles followed by sonication for 20 min to disrupt the milk fat globules. The cream-derived lipids, mainly triglycerides, were separated from the milk by centrifugation at $3,000 \mathrm{~g}$ for $1 \mathrm{~h}$ at $4^{\circ} \mathrm{C}$ and removed by filtration through glass wool. The resulting skimmed milk containing most of the original milk fat globule membrane was passed through a 300,000-D cutoff ultrafilter and was washed three times with distilled water (diafiltration) to remove the bulk of the smaller proteins from this fraction. The retentate was then dialyzed to remove any residual molecules smaller than $40,000 \mathrm{D}$, lyophilized, weighed, and tested for activity. The specific activity was calculated as the amount of protein from whole pooled milk that represented the minimum inhibitory concentration $\left(\mathrm{MIC}_{50}\right)^{1}$ divided by the amount of protein from a purified fraction that represented the $\mathrm{MIC}_{50}$.

Isoelectric focusing. Isoelectric focusing was performed in a Rotofor apparatus (Bio-Rad Laboratories). The macromolecular fraction, prepared as described above, was made $1 \%$ with ampholytes ( $\mathrm{pH} \mathrm{3-10)}$

1. Abbreviations used in this paper: $\mathrm{MIC}_{50}$, minimum inhibitory concentration; RSV, respiratory syncytial virus. in $50 \mathrm{ml}$ distilled water, and was resolved into 20 fractions at $14 \mathrm{~W}$ for 4 h. After the measurement of the $\mathrm{pH}$ with a standard $\mathrm{pH}$ electrode, each fraction was dialyzed against distilled water, lyophilized, and reconstituted with sterile PBS such that each purified material was at the concentration at which it was found in the original pooled-milk sample. The active fractions were pooled and refocused as above, but over a pH gradient of 3.9-7.1 over 20 fractions.

The highly focused fractions were tested for the presence of glycoproteins immunologically related to human milk mucin. This testing was performed by the binding of the fractions to the wells of the microtiter plates and by reaction with the Mc5 monoclonal antibody, which is directed at the milk mucin. The binding of the antibody was quantitated by reaction with peroxidase-labeled anti-mouse IgG and $o$-phenylene diamine $\mathrm{H}_{2} \mathrm{O}_{2}$ substrate (38).

The results of the immunoassays were expressed as specific inhibitory activity calculated by measuring the optical density at $450 \mathrm{~nm}$ generated by reactions in the wells coated with the milk fractions and subtracting the optical density generated in control wells that had not been coated with milk components.

The fractions generated by the preparative isoelectric focusing were tested for levels of IgG and secretory IgA immunoglobulins by a modification of previously described solid-phase enzyme immunoassay procedures (39). The fractions were also tested for the presence of trypsin inhibitory activity using benzoyl-DL-arginine- $p$-nitroanilide (BAPNA) substrate, following previously published procedures (40).

1 Purification of milk mucin components. Milk mucin complex in the delipidated human milk fat globules ( 38 ) was prepared by affinity chromatography using the Mc5 monoclonal antibody that recognizes the tandem repeat region of the human milk mucin, which is identical to breast mucin (41). The Mc5 monoclonal antibody was conjugated with cyanogen bromide-activated Sepharose-4B beads (Pharmacia) at a ratio of $1 \mathrm{mg}$ of $\mathrm{IgG} / \mathrm{ml}$ of swollen beads. The antibody-coated beads were washed and suspended in PBS containing $0.3 \%$ Triton X-100, $10 \%$ bovine serum, and $0.1 \%$ sodium azide. Delipidated human milk fat globule was dissolved in the same buffer, sonicated, and incubated with antibody-coated beads overnight at $4^{\circ} \mathrm{C}$. The beads were then washed three times alternately with $0.1 \mathrm{M} \mathrm{Na}$ acetate, $1 \mathrm{M} \mathrm{NaCl}, \mathrm{pH}$

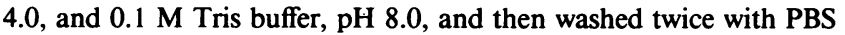
containing $0.3 \%$ Triton $\mathrm{X}-100$. The bound mucin complex was eluted with $3 \mathrm{M}$ sodium isocyanate and concentrated by dialysis.

To purify the individual components of the milk mucin complex (the milk mucin, and the 46- and 70-kD glycoproteins), delipidated milk fat globule was fractionated under reducing conditions $(0.5 \% \beta$ mercaptoethanol) by electrophoresis in a 3-15\% SDS polyacrylamide gel. One lane was stained with Coomassie blue to identify the components whereas the remaining gel was frozen. The reduced human milk mucin $(\sim 400 \mathrm{kD})$, the 70 -, and the $46-\mathrm{kD}$ components were individually excised from the gel, placed into dialysis bags, and eluted from the gel by electrophoresis under reducing conditions (gel running buffer containing $0.5 \%$ B-mercaptoethanol and $2 \mathrm{M}$ dithiothreitol). The eluted proteins were separated from the gel by centrifugation and characterized by reaction with the specific monoclonal antibodies (Mc5 for the milk mucin, Mc13 and Mc16 for the 70- and 46-kD glycoproteins, respectively) (38).

Sialic acid hydrolysis. The involvement of sialic acid in the inhibition of rotaviruses by milk mucin components was investigated by the chemical hydrolysis of sialic acid (desialylation) from the purified components using previously described methods (42-44). Briefly, samples containing 1-10 mg purified milk glycoprotein were suspended in $1 \mathrm{ml}$ $0.08 \mathrm{~N} \mathrm{H}_{2} \mathrm{SO}_{4}$ and digested for $1 \mathrm{~h}$ at $80^{\circ} \mathrm{C}$. After rapid cooling on ice, the samples were neutralized with $100 \mu \mathrm{l}$ of $0.8 \mathrm{M} \mathrm{NaOH}$. The samples were then dialyzed exhaustively and lyophilized. The residual glycoprotein was tested for its ability to bind to rotavirus as described below.

\section{Interaction of virus with milk components}

Solid phase-binding assay. The RRV (rhesus rotavirus MMU 18006) and SA-11 strains of simian rotavirus and the Wa, DS-1, P, and ST3 strains of human rotavirus were propagated in MA-104 cells using pre- 
viously described methods. By virtue of the major neutralization protein VP7, the simian strains belong to serotype 3 and the human strains Wa, Ds-1, P, and ST3 to serotypes 1, 2, 3, and 4, respectively (45). The viruses were diluted in PBS to concentrations of $\sim 10^{3} \mathrm{pfu} / \mathrm{ml}$ and immobilized onto the wells of microtiter plates previously coated with methylated bovine serum albumin (46). Wells were also coated with an equivalent concentration of uninfected MA-104 cells under identical conditions to serve as controls. After washing of the wells with PBS-Tween, the virus and controls were reacted with the mucin components, prepared as described above, and added at a concentration of 10 $\mu \mathrm{g} / \mathrm{ml}(0.5 \mu \mathrm{g}$ per well $)$.

Binding of the mucin components to the virus and controls was determined by reaction with monoclonal antibodies directed at the specific mucin components. The Mc5 monoclonal antibody was used for detection of the native mucin complex, the Mc13 monoclonal antibody was used for detecting the 70-kD glycoprotein component, and the Mc16 monoclonal antibody was used for detecting the 46-kD glycoprotein subunit (38). The reactions were quantitated by reaction with ${ }^{125}$ I-labeled anti-murine IgG and gamma counting.

Each component was measured in quadruplicate. For each component a specific-binding ratio was calculated by dividing the mean number of counts generated in the virus-coated well by the mean number of counts generated in cell control wells.

Replication in tissue culture. The fractions of milk prepared by the above methods were diluted in EMEM containing $0.5-1 \mu \mathrm{g} / \mathrm{ml}$ porcine trypsin and mixed with $\sim 100 \mathrm{pfu}$ of the indicated strain of rotavirus. After adsorption of the virus-milk factor mixture for $1 \mathrm{~h}$ at $37^{\circ} \mathrm{C}$, the cell monolayers were washed and covered with an agarose overlay containing $0.5 \mu \mathrm{g} / \mathrm{ml}$ trypsin plus the same concentration of antiviral milk factor as used in the adsorption. After $\sim 5 \mathrm{~d}$ of incubation at $37^{\circ} \mathrm{C}$, a second agarose overlay containing neutral red was added, and plaques were enumerated after visual inspection.

For each concentration of test milk factor, a percentage inhibition was calculated as $100 \times\left[1-\left(P_{\mathrm{f}} / P_{\mathrm{c}}\right)\right]$ where $P_{\mathrm{f}}$ is the number of plaques generated in cells infected with virus incubated with milk factor and $P_{\mathrm{c}}$ is the number of plaques generated in cells infected with virus in the absence of added factor.

Each fraction was initially tested at a concentration equivalent to that found in the milk pool. Samples that demonstrated inhibition were tested at log-fold dilutions. The $\mathrm{MIC}_{50}$ was calculated by interpolating the minimum concentration required for the $50 \%$ inhibition of plaque generation.

Prevention of experimental rotavirus gastroenteritis. We used a previously developed mouse model of rotavirus gastroenteritis to study the effect of milk components on the development of experimental rotavirus gastroenteritis $(34,40)$. The epizootic diarrhea of infant mice (EDIM) strain of murine rotavirus was purified by ultracentrifugation through $\mathrm{CsCl}$ and incubated at a concentration of $10 \mathrm{ID}_{100} / \mathrm{ml}$ with indicated milk components, at a concentration of $100 \mu \mathrm{g} / \mathrm{ml}$, or with control preparations. After incubation for $30 \mathrm{~min}$ at $37^{\circ} \mathrm{C}, 100 \mu \mathrm{l}$ of the milk-virus mixture was fed to each mouse in individual litters of suckling mice. The animals were observed for the development of diarrhea for 3 to $5 \mathrm{~d}$ after infection. The suckling mice continued to receive milk from their mothers during the course of the study. Control preparations consisted of a bovine milk-based infants' formula (Similac; Ross Laboratories, Columbus, $\mathrm{OH}$ ) as well as minimum essential media. To minimize variations among litters, the suckling mice were pooled and then randomly divided among the dams immediately before inoculation. The suckling mice remained with these dams throughout the course of the study.

\section{Results}

Initial experiments were directed at determining the fractions of human milk that contain antirotaviral activity. We purified the oligosaccharide, lipid, and macromolecular protein fractions from a pool of milk obtained from 30 healthy donors and diluted the fractions to one tenth the volume of milk from which they were isolated (i.e., 10-fold more concentrated then the original milk pool). We then tested the fractions for the ability to inhibit the replication of the SA-11 strain of rotavirus in tissue culture at 10-fold the concentrations found in human milk, at the concentration found in milk, and at logarithmic dilutions $(1: 10,1: 100,1: 1,000,1: 10,000$, etc.). None of the oligosaccharide or lipid components of milk displayed significant levels of antirotavirus activity at any measured concentrations. However, the macromolecular fraction $(>300 \mathrm{kD})$ inhibited the replication of the prototype SA-11 strain (VP7 serotype 3 ) of rotavirus with a minimum inhibitory concentration of $\sim 100 \mu \mathrm{g} / \mathrm{ml}$ (Fig. 1). This corresponds to a threefold increase in specific activity compared with the original milk pool. We also found that the macromolecular fraction of human milk, tested at a concentration of $250 \mu \mathrm{l} / \mathrm{ml}$, could inhibit the in vitro replication of four human strains of rotavirus representing VP7 serotypes 1-4 (Fig. 2). In the case of all four virus strains, the inhibition was reduced or abolished by the chemical desialylation of the milk glycoprotein. The macromolecular fraction of human milk was further fractionated by high-resolution preparative isoelectric focusing (14). As depicted in Fig. 3 , we found that the rotavirus inhibitory activity was confined to fractions with pI ranging from 4.0 to 4.6. These fractions did not contain immunoglobulins detectable by solid-phase immunoassay nor protease inhibitory activity detectable by reaction with trypsin and BAPNA substrate. However, the fractions with antiviral activity reacted with monoclonal antibodies directed at the human milk mucin complex. The acidic fractions with antirotaviral activity were pooled and subsequently designated as the acidic glycoprotein fraction of human milk. We found that this acidic glycoprotein fraction could inhibit the replication of the SA-11 strain of rotavirus at a concentration

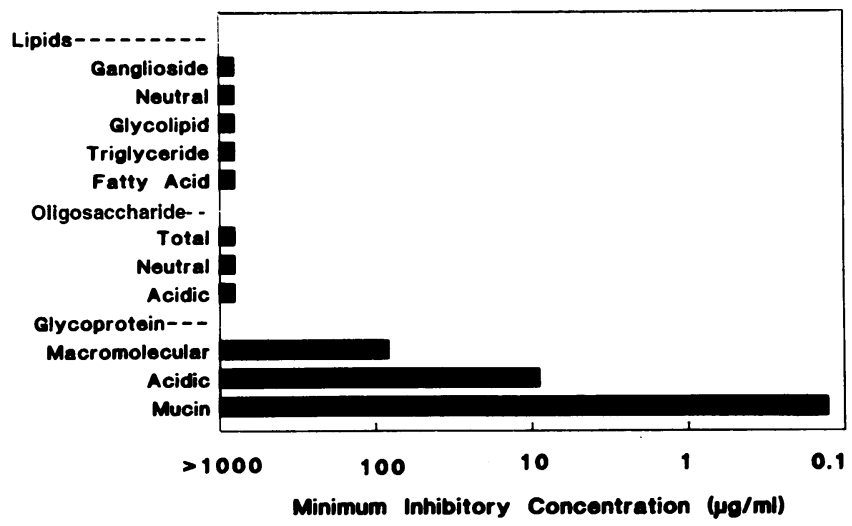

Figure 1. Effect of the human milk components on rotavirus replication. Fractions of human milk were prepared and tested for the ability to inhibit the replication of the SA-11 strain of rotavirus in MA-104 cells as described in the text. Each fraction was initially tested at a concentration equivalent to that found in the milk pool and at 10 times that concentration. Samples that demonstrated inhibition were tested at log-fold dilutions. Bars indicate the minimum concentration required for 50\% inhibition of SA-11 plaque generation in MA-104 cells. 


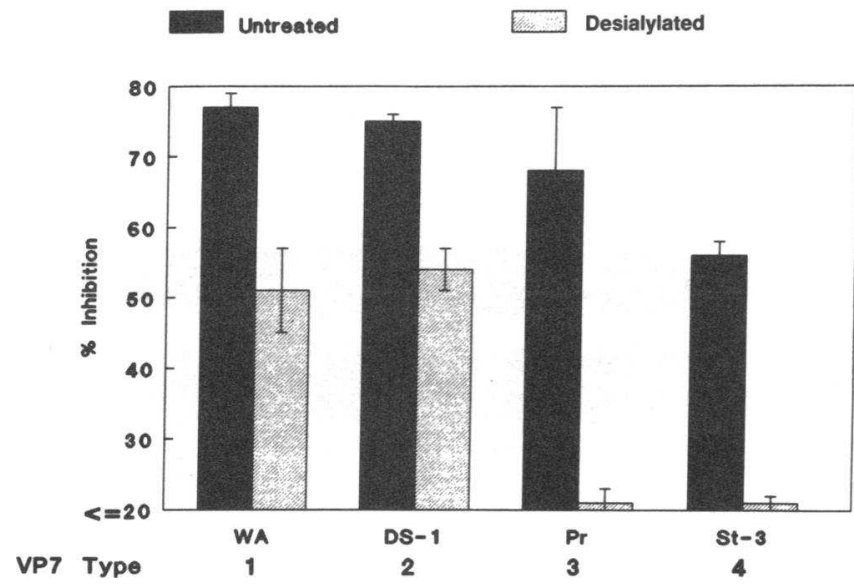

Figure 2. Inhibition of human rotavirus. The indicated strains of human rotaviruses were incubated with the human macromolecular glycoprotein at a concentration of $250 \mu \mathrm{l} / \mathrm{ml}$ and propagated in MA104 cells as described in the text. The viruses were also incubated with the same concentration of the macromolecular fraction, which had been chemically desialylated by the methods described in the text. After the addition of agarose overlay containing the same concentration of the homologous macromolecular fraction, the number of plaques were enumerated and compared with that of the same viral strain propagated in the absence of added fractions. The bars indicate the mean \pm range of the measured inhibition in plaque generation.

of $8 \mu \mathrm{g} / \mathrm{ml}$ ( $1: 500$ dilution from its original concentration in milk, a 38-fold increase in specific activity) (Fig. 1).

We further purified the active milk glycoprotein by means of affinity chromatography using a monoclonal Mc5 antibody

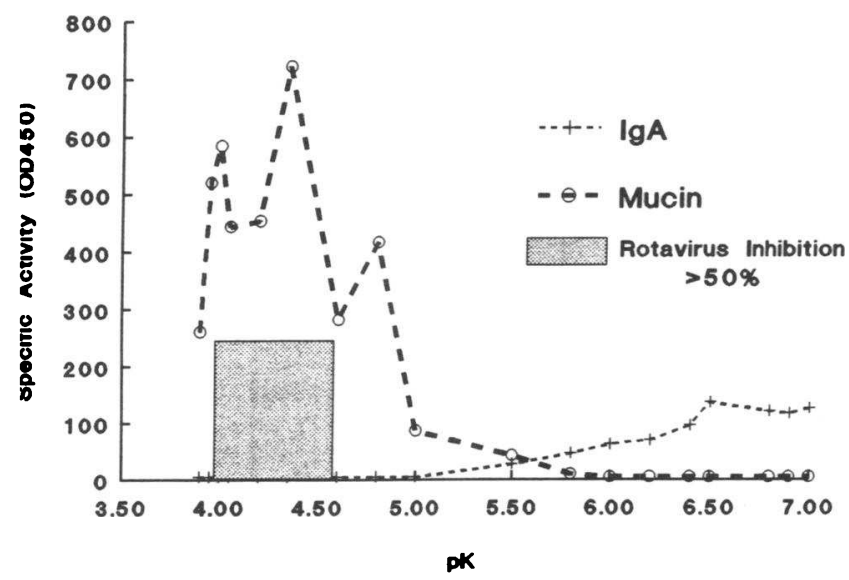

Figure 3. Isoelectric focusing of the human milk macromolecular somponent. The human milk macromolecular fraction was separated sy isoelectric focusing using a Rotofor apparatus as described in the ext. The active fractions over a pH 3-11 gradient were pooled and efocused over a pH 3.9-7.1 gradient of ampholytes. These fractions vere measured for Mc5 epitopes, IgA epitopes, and rotavirus inhibiion in vitro. The open circles indicate the reactivity of each fraction o the monoclonal antibody Mc5 directed at milk mucin, measured y enzyme immunoassay as described in the text. The crosses indicate he levels of IgA in each fraction as determined by enzyme immunossay. The shaded area indicates fractions that displayed $>50 \%$ inhirition of 100 plaque-forming units of the SA-11 strain of rotavirus, ultivated in MA-104 as described in the text. directed at the human milk mucin complex (38). We found that the affinity-purified milk mucin complex inhibits the replication of SA-11 virus at a concentration of $0.1 \mu \mathrm{g} / \mathrm{ml}$, or a 3,000-fold increase in specific activity (Fig. 1). Deglycosylation of the mucin complex by treatment with hydrogen fluoride for $3 \mathrm{~h}$ at room temperature, conditions that result in the hydrolysis of most glycosidic bonds, resulted in a substantial reduction in rotavirus inhibitory activity. No significant inhibition was measurable at $10 \mu \mathrm{g} / \mathrm{ml}$, the highest concentration of the deglycosylated mucin that was available for testing.

We also investigated the binding of the milk mucin complex to rotavirus proteins in a solid-phase radio-binding assay. As depicted in Fig. 4, we found that the native affinity-purified milk mucin complex binds specifically to cells infected with the SA-11 strain of rotavirus. We further fractionated the milk mucin complex under reducing conditions that result in the dissociation of the complex. We found that, after such treatment, specific rotavirus binding was associated with the $46-\mathrm{kD}$ component of the mucin complex; significant binding was not found with the $70-\mathrm{kD}$ glycoprotein component nor with the reduced macromolecular mucin, which did not contain the associated components.

We also found that the 46-kD component bound to simian rotavirus strain $R R V$ (VP7 serotype 3 ) and to human rotavirus strains Wa, DS-1, P, and ST3, (VP7 serotypes 1, 2, 3, and 4, respectively (Fig. 5). The 46-kD component bound to each of the human strains with approximately equal avidity. The level of binding of the 46-kD component to the human strains did

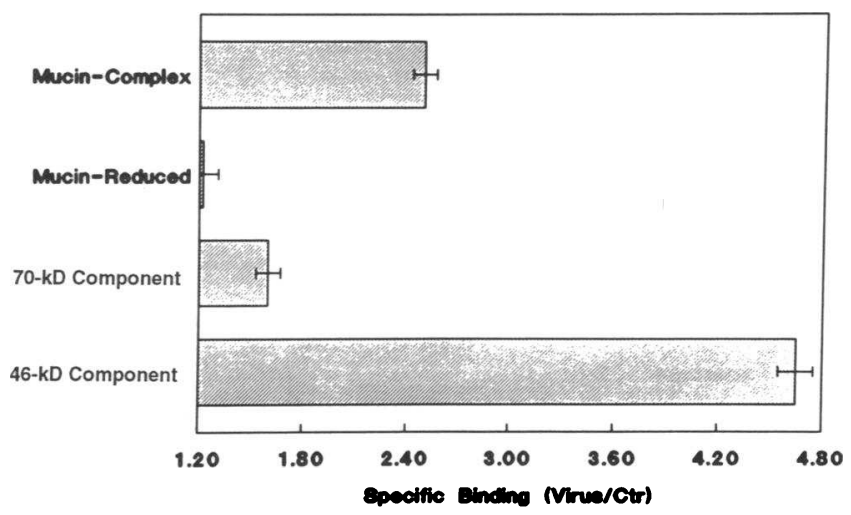

Figure 4. Binding of rotavirus to human milk mucin components. Aliquots of MA-104 cells infected with the RRV strain of rotavirus were immobilized onto the wells of microtiter plates previously coated with methylated bovine serum albumin (46). Additional wells were coated with uninfected MA-104 cells to serve as controls. The virus and control wells were reacted with native affinity-purified milk mucin complex or with mucin components purified from the native complex by preparative gel electrophoresis under reducing conditions as described in the text. Binding of the mucin components to the virus-infected and control cells was determined by reaction with monoclonal antibodies (Mc5, Mc13, Mc16) directed at mucin components followed by ${ }^{125}$ I-labeled anti-murine IgG. The plotted values indicated the mean of quadruplicate determinations calculated by dividing the mean number of counts generated in the wells coated with virus-infected cells by the mean number of counts generated in the wells coated with uninfected MA-104 cells (V/C ratio). The error bars indicate the standard deviation of each mean expressed in a similar manner. 


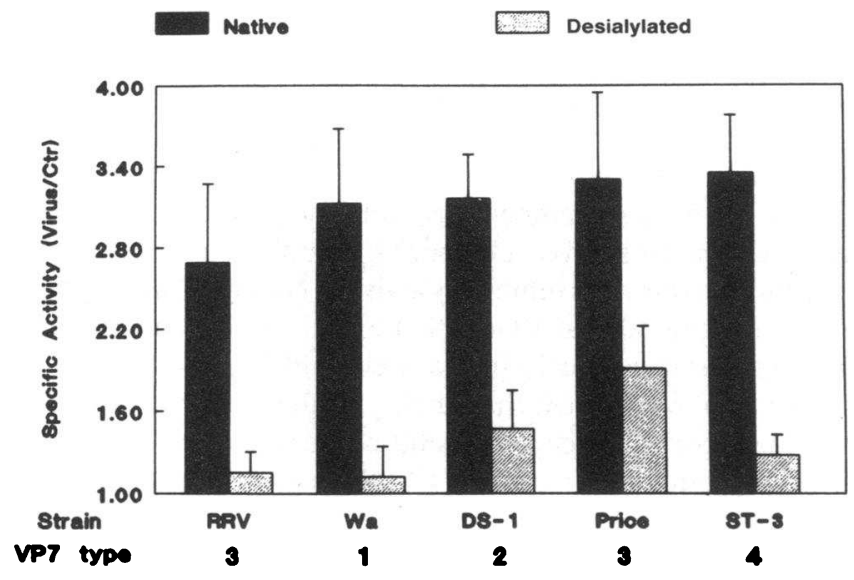

Figure 5. Binding of rotaviruses to human milk $46-\mathrm{kD}$ component. The indicated rotavirus strains were cultivated in MA-104 cells and immobilized onto microtiter plates as described for Fig. 3. The immobilized virus and uninfected control cells were reacted with native and desialylated $46-\mathrm{kD}$ human milk glycoprotein prepared as described in the text. Binding of the 46-kD components to the virus and control wells was determined by reaction with the Mc16 monoclonal antibody directed at the peptide portion of the $46-\mathrm{kD}$ glycoprotein followed by ${ }^{125}$ I-labeled anti-murine IgG. The plotted values indicated the mean of quadruplicate determinations calculated by dividing the mean number of counts generated in the wells coated with virus-infected cells by the mean number of counts generated in the wells coated with uninfected MA-104 cells (V/C ratio). The error bars indicate the standard deviation of each mean, expressed in a similar manner.

not differ significantly from the level of binding to the simian strain. As depicted in Fig. 5, the chemical hydrolysis of sialic acid resulted in a substantial decrease in binding of the 46-kD glycoprotein to the rhesus rotavirus strain as well as to all of the other rotavirus strains that were evaluated (all $P<0.01$; twotailed $t$ test). It should be noted that, since these binding studies were performed with virus-infected cells rather than with purified virions, the possibility that the $46-\mathrm{kD}$ component is binding to cellular proteins, which are upregulated during the course of viral infection, cannot be totally excluded. The molecular nature of the interaction between milk, viral, and cellular components is the subject of ongoing investigations.

We also tested the efficacy of feeding milk components on the prevention of rotavirus gastroenteritis in a mouse model of rotavirus infection. As depicted in Fig. 6, the macromolecular fraction of human milk totally prevented the development of rotavirus gastroenteritis in the animal model. Furthermore, feeding the milk acidic glycoprotein component along with rotavirus resulted in $>90 \%$ protection against symptomatic gastroenteritis. On the other hand, neither infant formula based on cow milk or tissue culture media resulted in measurable protection against symptomatic infection.

\section{Discussion}

These studies document that nonimmunoglobulin components of human milk inhibit the in vitro replication of rotaviruses and can prevent the development of rotavirus gastroenteritis in an animal model of rotavirus infection. We found that

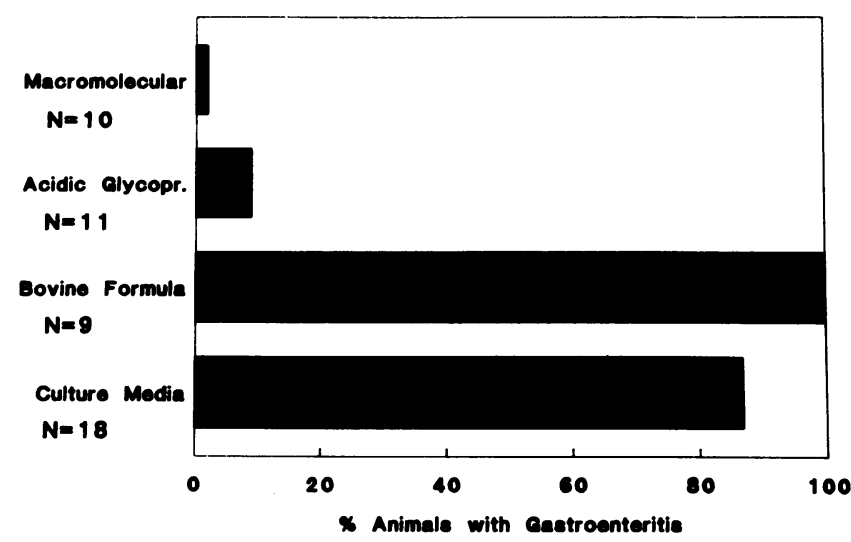

Figure 6. Efficacy of milk components for the prevention of experimental rotavirus gastroenteritis. The EDIM strain of murine rotavirus was incubated with the indicated milk or control components and fed to suckling mice. The animals were observed for the development of gastroenteritis for 3 to 5 days after infection. The bars indicate the percentage of animals that developed clinically apparent rotavirus gastroenteritis and the numbers adjacent to the bars indicate the numbers of animals used for each experiment. The macromolecular and acidic glycoprotein components of milk were tested at concentrations of $100 \mu \mathrm{g} / \mathrm{ml}$. The bovine milk formula and the tissue culture media were tested without dilution.

a substantial proportion of the antiviral activity is associated with fractions that contain milk mucin complex. Human milk mucin is a highly glycosylated macromolecule consisting of $50 \%$ carbohydrate, most of which is $O$-linked. In its native state, human milk mucin is found complexed with several smaller molecules, including a disulfide-linked 70-kD glycoprotein and a 46-kD glycosylated component (47-51). The biological functions of the milk mucin and the associated subunits have not been fully defined.

We found that the native human milk mucin complex inhibits rotavirus replication at concentrations as low as $0.1 \mu \mathrm{g} /$ $\mathrm{ml}$ ( $\sim 2 \times 10^{-10} \mathrm{~mol} /$ liter, based on a molecular weight of $500,000)$. The affinity-purified material cannot be directly compared to its concentration in the original milk because of the nonquantitative nature of the purification scheme. However, the 3,000-fold increase in specific activity indicates that this molecule has extremely high ability to block rotavirus replication. Furthermore, the complex binds to rotavirus, as measured in a solid phase-binding assay. Upon reduction and separation of the mucin components by polyacrylamide gel electrophoresis, a substantial portion of the viral-binding activity was found to be associated with the $46-\mathrm{kD}$ glycoprotein subunit of the milk mucin complex. This $46-\mathrm{kD}$ molecule is of interest because of its extended regions of homology in the $\mathrm{C}, \mathrm{C} 2$ region (phospholipid-binding region) of human clotting factors $\mathrm{V}$ and VIII, and its several potential $O$-linked and $N$-linked glycosylation sites ( 51 ). The 46-kD glycoprotein appears to be linked to the mucin complex by an unknown mechanism but does copurify with the complex under the nondenaturing conditions employed for the affinity-purification experiments. The relative importance of the milk mucin components in the antiviral activity of the human milk mucin complex is the subject of ongoing investigations; these determinations will require the generation of the purified $46-\mathrm{kD}$ component in sufficient 
quantities for the performance of studies using cell culture and animal model systems.

This report does not address the molecular mechanisms of action of the antiviral milk glycoproteins. However, it is of note that we found that the chemical hydrolysis of sialic acid from the milk mucin and from the 46-kD glycoprotein component substantially reduced rotavirus binding. We chose to use chemical, as opposed to enzymatic, hydrolysis as previous studies with bovine mucins indicated that some sialidases might not remove the specific linkages involved in viral binding and neutralization (35).

The specificity of a chemical method for the hydrolysis of glycosidic linkages is dependent upon the reaction conditions that are employed. The glycosidic linkages of sialic acid residues of glycoproteins are uniquely sensitive to mild acid hydrolysis. However, the use of $0.1 \mathrm{~N}$ of hydrochloric acid results in the destruction of $20 \%$ of acylneuraminic acids released during acid hydrolysis of erythrocyte membranes (52). Thus the use of dilute sulfuric acid for the hydrolysis of sialic acid is preferred due to its specificity for the glycosidic linkage. The release of sialic acids from human serum and brain was optimal with $0.1 \mathrm{~N}$ sulfuric acid at $80^{\circ} \mathrm{C}$ for $1 \mathrm{~h}$, depending on the concentration of sialic acids in the sample (53). For bovine cervical mucopolysaccharide, human cervical mucopolysaccharide, and dilute goat serum, $1 \mathrm{~h}$ was the optimum time of hydrolysis for $0.1 \mathrm{~N} \mathrm{H}_{2} \mathrm{SO}_{4}$ at $80^{\circ} \mathrm{C}(42)$. These conditions were also used for the analysis of sialic acids in a wide variety of biological samples $(44,54)$. On the other hand, optimum release of sialic acids from rabbit Tamm-Horsfall glycoprotein occurred with digestion with $0.5 \mathrm{M} \mathrm{H}_{2} \mathrm{SO}_{4}$ at $80^{\circ} \mathrm{C}$ for $1 \mathrm{~h}$ (55). These more mild conditions were also used to effect the release of sialic acid from the thyroglobulins of several species before their quantitation (56). In animal glycoproteins, the glycosidic linkage involving fucose is also exceptionally sensitive to acid hydrolysis; the minimum conditions for the optimum release of fucose during acid hydrolysis are $0.6 \mathrm{~N} \mathrm{H}_{2} \mathrm{SO}_{4}$ at $100^{\circ} \mathrm{C}$ for $60 \mathrm{~min}$. Thus, we selected conditions for acid hydrolysis $(0.08$ $\mathrm{N} \mathrm{H}_{2} \mathrm{SO}_{4}, 80^{\circ} \mathrm{C}, 60 \mathrm{~min}$ ) with the highest likelihood for the specific but complete release of sialic acid, a calculated release of $\sim 3 \%$ of the fucose (43) and negligible release of other sugars.

It is of note that the chemical hydrolysis of the sialic acids from the $46-\mathrm{kD}$ component reduced binding to rotavirus strains, which are reported not to hemagglutinate erythrocytes or to bind to other sialic acid-containing compounds (57). It is thus possible that the linkages involved in viral binding to the 46-kD human milk component are different from those present on erythrocytes and other sialic acid-containing compounds. An alternative possibility is that the virus does not bind directly to a sialic acid-containing portion of the target molecule, but the removal of sialic acid results in a conformational alteration of the $46-\mathrm{kD}$-binding epitope. The possibility that the chemical hydrolysis of the $46-\mathrm{kD}$ glycoprotein eliminated reactivity of the MCl6 monoclonal antibody to solidphase glycoprotein is unlikely in light of the fact that this antibody is known to recognize a peptide domain of the glycoprotein (38). Furthermore, monoclonal antibody binding to the 46-kD glycoprotein can be demonstrated after chemical desialylation. The exact sugar specificities that determine rotavirus binding to the $46-\mathrm{kD}$ glycoprotein and to other glycoproteins of human and animal origin is the subject of ongoing investigations.
It is of note that a macromolecular component of human milk has been shown to inhibit the replication of respiratory syncytial virus ( $\mathrm{RSV}$ ). This $>400-\mathrm{kD}$ material retains its antiviral activity even when immunoglobulins are removed by affinity chromatography (58). It is thus possible that this macromolecular component has similarities to the macromolecular components that we identified as having antirotavirus activity. The surface glycoproteins of RSV are heavily glycosylated and treatment with a range of glycosidic enzymes markedly reduces viral infectivity; however, the role of specific sugar moieties in the interactions between RSV and cellular receptors have not been defined precisely $(59,60)$. Further studies of the antiRSV and antirotavirus macromolecules will allow for the more precise comparison of these antiviral milk factors. It is possible that highly glycosylated milk mucins and associated proteins are capable of inhibiting the replication of a wide range of viruses that use similar cellular binding mechanisms. Additional studies will be required to determine the role of milk mucins in the replication of other pathogenic agents.

Our data indicate that acidic protein molecules are the major nonimmunoglobulin components of human milk with antirotaviral activity. Previous studies have indicated that rotaviruses bind to purified glycolipid compounds (61) and that milk lipids inhibit the replication of other viruses (31). However, we did not find evidence of rotavirus inhibitory activity in the lipid fractions of the milk that we examined. The possibility that other methods of isolation might result in the identification of milk lipids with antirotaviral activity should be the subject of additional investigations.

Our studies document that human milk mucinous glycoproteins inhibit the replication of rotaviruses in tissue culture and can prevent the development of rotavirus gastroenteritis in an animal model of infection. Studies of individuals have indicated qualitative and quantitative variation in the mucins present in human milk (62). It is thus possible that the levels of antirotaviral factors will vary depending upon genetic, nutritional, or environmental factors; these differences might explain the variable effects of breast-feeding on rotavirus infection noted in different populations (24-30). It is also possible that different strains of rotaviruses will display variable degrees of inhibition by milk glycoproteins, possibly related to varying degrees of affinity for sialic acid-containing cellular receptors (57).

The further definition of the structure-function relationships of antiviral glycoproteins in human milk and of their mechanisms of action may allow for disease susceptibility in breast-fed infants to be predicted, either on the basis of direct measurement of the relevant milk component or on the basis of the underlying genetic correlates of such variation. Furthermore, the precise characterization of the antiviral glycoproteins might allow for the generation of large quantities of antirotaviral materials from human, bovine, microbial, or synthetic sources. These compounds may form the basis for new therapeutic modalities for the prevention and treatment of gastrointestinal infections in children who cannot be breast-fed and in other individuals at high risk for viral gastroenteritis.

\section{Acknowledgments}

We thank Mary Jett-Goheen and Barbara Clayman for technical contributions and Ann Cusic for administrative and secreterial assistance. 
Work performed by Johns Hopkins supported by Grant R01 DK 33089 from the National Institute of Diabetes and Digestive and Kidney Diseases and HD29277 from the National Institute of Child Health and Human Development, National Institutes of Health. Dr. Midthun's work is supported by Burroughs Wellcome Young Investigator Award in Virology of the Infectious Diseases Society of America. Work performed by Cancer Research Fund of Contra Costa supported by grants CA39932 and CA42767 from the National Cancer Institute. Work performed by the Shriver Center for Mental Retardation supported by HD 13021 from the National Institute of Child Health and Human Development.

\section{References}

1. Ho, M., R. I. Glass, P. F. Pinsky, and L. J. Anderson. 1988. Rotavirus as a cause of diarrheal morbidity and mortality in the United States. J. Infect. Dis. 158:1112-1116.

2. Ho, M., R. I. Glass, P. F. Pinsky, Y. Nacole, W. M. Sappenfield, J. W. Buehler, N. Gunter, and L. J. Anderson. 1988. Diarrheal deaths in American children. Are they preventable? JAMA (J. Am. Med. Assoc.). 22:3281-3285.

3. Snyder, J. D., and M. H. Merson. 1982. The magnitude of the global problem of acute diarrhoeal disease: a review of active surveillance data. Bull. WHO. 60:605-613.

4. Guerrant, R. L., J. M. Hughes, N. L. Lima, and J. Crane. 1990. Diarrhea in developed and developing countries: magnitude, special settings, and etiologies. J. Infect. Dis. 12:S41-S50.

5. Blacklow, N. R., and H. B. Greenberg. 1991. Viral gastroenteritis. N. Engl. J. Med. 325:252-264.

6. Treanor, J., and R. Dolin. 1990. Viral infections of the gastrointestinal tract. In Antiviral Agents and Viral Diseases of Man. G. J. Galasso, R. J. Whitley, and T. C. Merigan, editors. Raven Press, Ltd., New York. 373-414.

7. Rodriguez, W. J., H. W. Kim, C. D. Brandt, R. H. Schwartz, M. K Gardner, B. Jeffries, R. H. Parrott, R. A. Kaslow, J. I. Smith, and A. Z. Kapikian. 1987. Longitudinal study of rotavirus infection and gastroenteritis in families served by a pediatric medical practice: clinical and epidemiologic observations. Pediatr. Infect. Dis. J. 6:170-176.

8. Halvorsrud, J., and I. Orstavik. 1980. An epidemic of rotavirus-associated gastroenteritis in a nursing home for the elderly. Scand. J. Infect. Dis. 12:161164.

9. Saulsbury, F. T., J. A. Winkelstein, and R. H. Yolken. 1980. Chronic rotavirus infection in immunodeficiency. J. Pediatr. 97:61-65.

10. Yolken, R. H., C. A. Bishop, T. R. Townsend, E. A. Bolyard, J. Bartlett, G. W. Santos, and R. Saral. 1982. Infectious gastroenteritis in bone-marrowtransplant recipients. $N$. Engl. J. Med. 306:1009-1012.

11. Pickering, L. K., D. G. Evans, H. L. DuPont, J. J. Vollet, and D. J. Evans, Jr. 1981. Diarrhea caused by Shigella, rotavirus, and Giardia in day care centers: prospective study. J. Pediatr. 99:51-56.

12. Marrie T. J., S. H. S. Lee, R. S. Faulkner, J. Ethier, and C. H. Young 1982. Rotavirus infection in a geriatric population. Arch. Intern. Med. 142:313316.

13. Clark, H. F., F. E. Borian, L. M. Bell, K. Modesto, V. Gouvea, and S. A Plotkin. 1988. Protective effect of WC3 vaccine against rotavirus diarrhea in infants during a predominantly serotype 1 rotavirus season. J. Infect. Dis. 158:570-587.

14. Newburg, D. S., R. P. Viscidi, A. Ruff, and R. H. Yolken. 1992. A human milk factor inhibits binding of human immunodeficiency virus to the CD4 receptor. Pediatr. Res. 31:22-28.

15. Gothefors, L., G. Wadell, P. Juto, K. Taniguchi, A. Z. Kapikian, and R. I. Glass. 1989. Prolonged efficacy of rhesus rotavirus vaccine in Swedish children. J. Infect. Dis. 159:753-757.

16. Bernstein, D. I., V. E. Smith, D. S. Sander, K. A. Pax, G. M. Schiff, and R. L. Ward. 1990. Evaluation of WC3 rotavirus vaccine and correlates of protection in healthy infants. $J$. Infect. Dis. 162:1055-1062.

17. Santosham, M., W. G. Letson, M. Wolff, R. Reid, S. Gahagan, R. Adams, C. Callahan, R. B. Sack, and A. Z. Kapikian. 1991. A field study of the safety and efficacy of two candidate rotavirus vaccines in a native American population. $J$. Infect. Dis. 163:483-487.

18. Chitkara, I. 1961. Infant feeding and mortality in an Indian village. Prev Med. Epid. 145:361.

19. Mata, L. J., R. A. Kronmal, B. Garcia, W. Butler, J. J. Urrutia, and S. Murillo. 1976. Breast-feeding, weaning and the diarrhoeal syndrome in a Guatemalan Indian village. Ciba Found. Symp. 42:311-338.

20. Jason, J. M., P. Nieburg, and J. S. Marks. 1984. Mortality and infectious disease associated with infant-feeding practices in developing countries. Pediatrics. 74:702-727.

21. Howie, P. W., J. S. Forsyth, S. A. Ogston, A. Clark, and C. D. Florey. 1990. Protective effect of breast feeding against infection. Br. Med. J. 300:11-16. 659

22. Cunningham, A. S. 1987. Breast-feeding and health. J. Pediatr. 110:658-

23. Lucas, A., and T. J. Cole. 1990. Breast milk and neonatal necrotising enterocolitis. Lancet. 336:1519-1523.

24. Gurwith, M., W. Wenman, D. Gurwith, J. Brunton, S. Feltham, and H Greenberg. 1983. Diarrhea among infants and young children in Canada: a longitudinal study in three northern communities. J. Infect. Dis. 147:685-692.

25. Glass, R. I., and B. J. Stoll. 1989. The protective effect of human milk against diarrhea. A review of studies from Bangladesh. Acta Paediatr. Scand. Suppl. 351:131-136.

26. Weinberg, R. J., G. Tipton, W. J. Klish, and M. R. Brown. 1984. Effect of breast-feeding on morbidity in rotavirus gastroenteritis. Pediatrics. 74:250-253.

27. Duffy, L. C., M. Riepenhoff-Talty, T. E. Byers, L. J. La-Scolea, M. A. Zielezny, D. M. Dryja, and P. L. Ogra. 1986. Modulation of rotavirus enteritis during breast-feeding. Implications on alterations in the intestinal bacterial flora. Am. J. Dis. Child. 140:1164-1168.

28. Berger, R., F. Hadziselimovic, M. Just, and F. Reigel. 1984. Influence of breast milk on nosocomial rotavirus infections in infants. Infection. 12:171-174.

29. Totterdell, B. M., K. G. Nicholson, J. MacLeod, I. L. Chrystie, and J. E. Banatvala. 1982. Neonatal rotavirus infection: role of lacteal neutralising alpha $1-$ anti-trypsin and nonimmunoglobulin antiviral activity in protection. $J$. Med. Virol. 10:37-44.

30. Jayashree, S., M. K. Bhan, R. Kumar, N. Bhandari, and S. Sazawal. 1988. Protection against neonatal rotavirus infection by breast milk antibodies and trypsin inhibitors. J. Med. Virol. 26:333-338.

31. Isaacs, C. E., S. Kashyap, W. C. Heird, and H. Thormar. 1990. Antiviral and antibacterial lipids in human milk and infant formula feeds. Arch. Dis. Child. 65:861-864.

32. Okamoto, Y., and P. L. Ogra. 1989. Antiviral factors in human milk: implications in respiratory syncytial virus infection. Acta Paediatr. Scand. Suppl. 351:137-143.

33. Goldman, A. S., and R. M. Goldblum. 1990. Human milk: immunologicnutritional relationships. Ann. NY Acad. Sci. 587:236-245.

34. Yolken, R. H., R. Willoughby, S.-B. Wee, R. Miskuff, and S. Vonderfecht. 1987. Sialic acid glycoproteins inhibit the in vitro and in vivo replication of rotaviruses. J. Clin. Invest. 79:148-154.

35. Willoughby, R. E., and R. H. Yolken. 1990 . SA11 rotavirus is specifically inhibited by an acetylated sialic acid. J. Infect. Dis. 161:116-119.

36. Bass, D. M., E. R. Mackow, and H. B. Greenberg. 1991. Identification and partial characterization of a rhesus rotavirus binding glycoprotein on murine enterocytes. Virology. 183:602-610.

37. Newburg, D. S., L. K. Pickering, R. H. McCluer, and T. G. Cleary. 1990 Fucosylated oligosaccharides of human milk protect suckling mice from heatstable enterotoxin of Escherichia coli. J. Infect. Dis. 162:1075-1080.

38. Peterson, J. A., D. T. Zava, A. K. Duwe, E. W. Blank, H. Battifora, and R. L. Ceriani. 1990. Biochemical and histological characterization of antigens preferentially expressed on the surface and cytoplasm of breast carcinoma cells identified by monoclonal antibodies against the human milk fat globule. $\mathrm{Hybrid}$ oma. 9:221-235.

39. Yolken, R. H., R. G. Wyatt, L. Mata, J. J. Urrutia, B. Garcia, R. M. Chanock, and A. Z. Kapikian. 1978. Secretory antibody directed against rotavirus in human milk-measurement by means of enzyme-linked immunosorbent assay. J. Pediatr. 93:916-921.

40. Vonderfecht, S. L., S.-B. Wee, R. L. Miskuff, R. R. Tidwell, and R. H. Yolken. 1988. Protease antagonists inhibit the in vitro and in vivo replication of rotavirus. J. Clin. Invest. 82:2011-2016.

41. Peterson, J. A., D. Larocca, G. Walkup, R. Amiya, and R. L. Ceriani. 1991. Molecular analysis of epitope heterogeneity of the breast mucin. In Breas Epithelian Antigens: Molecular Biology to Clinical Applications. R. L. Ceriani, editor. Plenum Publications, New York. 55-68.

42. Gibbons, R. A. 1963. The sensitivity of the neuraminosidic linkage in mucosubstances towards acid and towards neuraminidase. Biochem. J. 89:380 391 .

43. Gyorky, G., and J. C. Houck. 1965. The determination of terminal protein-bound fucose. Can. J. Biochem. 43:1807-1811.

44. Jourdian, G. W., L. Dean, and S. Roseman. 1971. The sialic acids; XI. A periodate-resorcinol method for the quantitative estimation of free sialic acids and their glycosides. J. Biol. Chem. 246:430-435.

45. Moshino, Y., R. G. Wyatt, H. B. Greenberg, J. Flores, and A. Z. Kapikian 1984. Serotypic similarity and diversity of rotaviruses of mammalian origin as studied by plaque reduction neutralization. J. Infect. Dis. 149:694-702.

46. Coriani, R. L. 1984. Solid phase identification and molecular weight determination of cell membrane antigens with monoclonal antibodies. In Monoclona Antibodies and Functional Cell Lines. Progress and Applications. K. B. Bechtol, T. J. McKern, and R. Kennett, editors. Plenum Press, New York. 398-402.

47. Shimizu, M., K. Yamauchi, Y. Miyauchi, T. Sakurai, K. Tokugawa, and R. A. Mcllhinney. 1986. High-Mr glycoprotein profiles in human milk serum and fat globule membrane. Biochem. J. 233:725-730.

48. Wreschner, D. H., M. Hareuveni, I. Tsarfaty, N. Smorodinsky, J. Horev, 
J. Zaretsky, P. Kotkes, M. Weiss, R. Lathe, A. Dion, et al. 1990. Human epithelial tumor antigen cDNA sequences. Differential splicing may generate multiple protein forms. Eur. J. Biochem. 189:463-473.

49. Duwe, A. K., and R. L. Ceriani. 1989. Human milk fat globule membrane derived mucin is a disulfide-linked heteromer. Biochem. Biophys. Res. Commun. 165:1305-1311.

50. Larocca, D., J. A. Peterson, G. Walkup, R. Urrea, and R. L. Ceriani. 1990 Cloning and sequencing of a complementary DNA encoding a Mr 70,000 human breast epithelial mucin-associated antigen. Cancer Res. 50:5925-5930.

51. Larocca, D., J. A. Peterson, A. Bistrain, R. Urrea, J. Kuniyoshi, and R. L. Ceriani. 1991. A $46 \mathrm{kDa}$ human milk fat globule glycoprotein that is highly expressed in carcinoma cells has homology with human clotting factors $\mathrm{V}$ and VIII. Cancer Res. 51:4994-4998.

52. Schauer, R., A. P. Corfield, M. Wember, and D. Danon. 1975. A micromethod for quantitative determination of acylneuraminic acids from erythrocyte membranes. Hoppe-Seyler's Physiol. Chem. 356:1727-1732.

53. Svennerholm, L. 1958. Quantitative estimation of sialic acids; III. An anion exchange resid method. Acta Chem. Scand. 12:547-554.

54. Warren, L. 1959. The thiobarbituric acid assay of sialic acids. J. Biol. Chem. 234:1971-1975.

55. Neuberger, A., and W. A. Ratcliffe. 1972. The acid and enzymic hydroly- sis of O-acetylated sialic acid residues from rabbit Tamm-Horsfall glycoprotein Biochem. J. 129:683-693.

56. Spiro, R. G., and M. J. Spiro. The carbohydrate composition of the thyroglobulins from several species. J. Biol. Chem. 240:997-1001.

57. Fukudome, N., O. Yoshie, and T. Konno. 1989. Comparison of human, simian, and bovine rotaviruses for requirement of sialic acid in hemagglutination and cell adsorption. Virology. 172:196-205.

58. Laegreid, A., A. B. Kolst-Otnaess, I. Orstavik, and K. H. Carlsen. 1986 Neutralizing activity in human milk fractions against respiratory syncytial virus. Acta Paediatr. Scand. 75:696-701.

59. Lambert, D. M. 1988. Role of oligosaccharides in the structure and function of respiratory syncytial virus glycoproteins. Virology. 164:458-466.

60. Wertz, G. W., M. Krieger, and L. A. Ball. 1989. Structure and cell surface maturation of the attachment glycoprotein of human respiratory syncytial virus in a cell line deficient in $O$ glycosylation. J. Virol. 63:4767-4776.

61. Willoughby, R. E., R. H. Yolken, and R. L. Schnaar. 1990. Rotaviruses specifically bind to the neutral glycosphingolipid asialo-GM1. J. Virol. 64:48304835.

62. Patton, S., G. Huston, R. Jenness, and Y. Vaucher. 1990. Differences between individuals in high-molecular weight glycoproteins from mammary epithelia of several species. Biochim. Biophys. Acta. 980:333-338. 